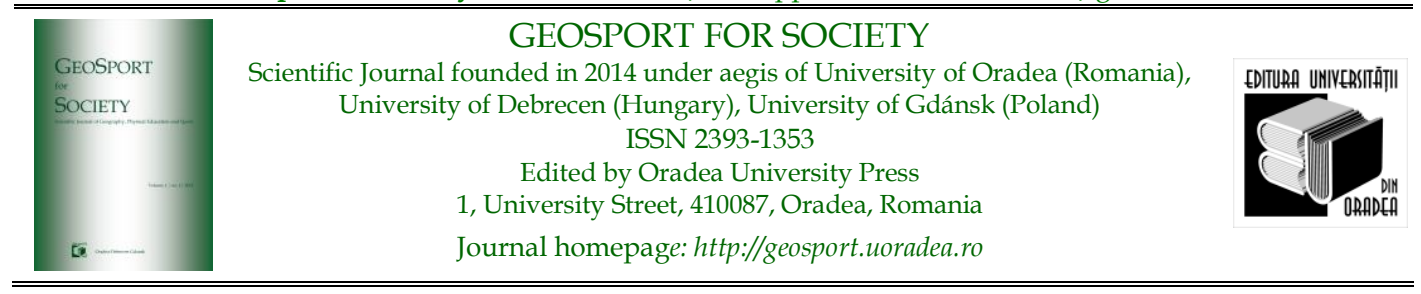

\title{
Fundamentals of beach volleyball blocking actions
}

\author{
Gabriel Alexandru PETROVICI 1*, Sorin ȘIMON 2
}

1. University “1 December 1918” Alba Iulia, Faculty of Law and Social Sciences, Department of Physical Education and Sport, Address: Str. Gabriel Bethlen, No. 5, Alba Iulia, C.P. 510009, Romania, e-mails: ducu petrovici@yahoo.com $\underline{\text { sorinsimonyah@yahoo.com }}$

* Corresponding author

Citation: Petrovici, G.A., \& Șimon, S. (2021). Fundamentals of beach volleyball blocking actions. Geosport for Society, 15(2), 90-100. https://doi.org/10.30892/gss.1503-075

Article history: 15.08.2021; Revised: 20.09.2021; Accepted: 05.10.2021, Available online: 13.10.2021

\begin{abstract}
Beach volleyball is spectacular with many rapid actions, agility moves, and high jumping. One of the key elements present in high-performance beach volleyball, having a decisive role in the defensive apparatus, is the blocking movements. This action is done mainly by the tallest player or with the most considerable jumping ability. A high blocking ability can facilitate the defensive movement of the player that is positioned in the back of the court. Blocking ability is facilitated by anticipation capacity, good sight, agility movement, and high jumping ability generated by solid legs. This paper analyses the fundamentals of blocking actions in beach volleyball, giving critical elements in executing a good and efficient block.
\end{abstract}

Keywords: blocking actions, beach volleyball, technique, training in beach volleyball

\section{Introduction}

In recent years, an increasing number of participants and tournaments have led to several studies on beach volleyball. In most cases, these studies analyzed the amount of energy used (Zetou et al., 2008), epidemiology, and lesion rehabilitation (Pfirrmann et al., 2008; Lajtai et al., 2009), kinematic analyzes of movement models (Tilp et al., 2008), physical performance (Sheppard et al., 2008; Riggs and Sheppard, 2009; Lidor and Ziv, 2010), body composition (Palao et al., 2008) and technical-tactical characteristics of the game (Koch and Tilp, 2009; López-Martínez and Palao, 2009).

The FIVB regulation describes blocking as "the action of players closes to the net to intercept the ball coming from opponents, reaching above the top edge of the net, regardless of the height of the point of contact of the ball. When in contact with the ball, part of the body must be above the upper edge of the net".

Blocking skill is a key technical element in beach volleyball which, together with the serve skill effectiveness, is directly related to obtaining the advantage in beach 
volleyball (Busca and Febrer, 2012; Jimenez-Olmedo et al., 2012; Marcelino et al., 2010; Peña et al., 2013). A challenging and consistent blocking action hinders the opposing team's attack (Castro et al., 2011). Blocking ability can also be improved by passing anxiety of competition and being bold; also, a psychologist can help every sport participant reach his or her potential as an athlete (Sopa, 2021; Popa et al., 2020).

In beach volleyball over the years, with its changes to the rules, the athlete should have an excellent physical condition, such as good speed (reaction and movement), agility, explosive power, and maximum strength (Bizzocchi, 2008; Lehnert et al., 2009; Pereira et al., 2015; Pastore et al., 2015). Scientists also discovered that group cohesion has a considerable influence on the performance and other fundamental factors in team sports life (Pomohaci and Sopa, 2018).

Sand impedes the movement of players (Smith, 2006), but due to this, players have developed specific movement patterns for beach volleyball (Cortell-Tormo et al., 2011; Perez-Turpin et al., 2009). Also, sand can remove the apparition of the spine, knee, and feet deficiency in the youth population (Szabo and Sopa, 2018).

Many studies analyze the anthropometrical characteristics of beach volleyball sportive regarding their playing position, in pro elite players (Jimenez-Olmedo et al., 2017; Palao et al., 2014) and other categories like youth (Ciccarone et al., 2005). Some of these analyses prove that players specialized in blocking actions have specific differences in body composition and somatotype; the research proved that they have superior height and weight and as well as a higher jumping ability and well-developed leg muscle system (Ciccarone et al., 2008; Marques et al., 2009). In the game of beach volleyball, players specialized in blocking actions present an increase in their weight and height, characteristics that are not as preeminent as for players specialized in defense actions (Palao et al., 2008). Also crucial in discovering the efficiency of volleyball actions is the statistical analysis of the game (Szabo and Sopa, 2020; Szabo et al., 2019; Sopa and Szabo, 2019).

It was noticed by each of us that in the game of beach volleyball, there is close communication and a certain automatism formed between the two players. Thus, before serving one of the team members, the other shows behind him sure signs that represent how the player who jumps to the block will defend himself against the opponent's attack. Under no circumstances is the blocking player allowed to return to the signs shown to his partner during the dispute before returning the ball to the game. This would confuse his teammate a lot, and he would not make his defense phase.

The purpose of the attack is to pass over or past the block, a quality that reflects the number of blocked attacks, the time of their blocking, and whether multiple blocks form a consistent barrier or, conversely, whether there are gaps or height differences that can be exploited by attackers (Afonso et al., 2008). Good jumping ability and static and dynamic balance can ease the block and give many other opportunities (Sopa, 2021; Sopa and Pomohaci, 2021).

The most important aspect is related to how the block will work on the defensive phase because depending on it, his back colleague builds his defense strategy. As for his physical stature, usually, the one who jumps to the block is the tallest player in the team but a little slower in moving on the sand, while the 
defensive phase behind the field is performed by a slightly shorter player who in turn benefits from an excellent move on the sand.

The signs that players repeatedly and usually make would be the following: both hands on the back, the left hand, and the right hand point the finger at each colleague at work. This indicates that the blocking player will jump and defend along the line where he is blocking, while his colleague will defend the diagonals.

If the blocking player points two fingers at each side, it means that he will jump on the block and try to defend the diagonals while his colleague has straight lines. If with the left hand he shows a finger and with the right, he shows two fingers, it means that the player on the left side will jump to the block and defend the right line, and on the right one, he will defend diagonally. If the sign made shows with the left hand the open palm and with the right hand the closed fist, it means most of the time that the player on the left will not jump to the block and will resort to a retreat along the line and the one on the right will jump to block and try to block the ball this leaves the defender alone to decide where to defend depending on the opponent. There are also situations of advanced players where each technical element has another difficulty implemented, the 3-finger and 4-finger sign, on the right block; however, he concentrates his jump and will stretch his arms diagonally in the hope that his opponent will fall into the trap. The sign-in in which four fingers are shown means that the player from the block will decide that he will no longer jump straight and will jump diagonally in the last second.

These signs are relatively standard and are used by players worldwide, but there are also cases where the two partners establish their signs known only to them that can be done in any way, without a rule in this regard.

An essential aspect is related to how the blocking player manages to mislead his opponents. Thus, if a player decides not to jump to the block, he must not show this too early in the course of the point. He must guard the net until he has noticed where the ball will go after the second contact of the opposing team, implicitly from the hand of the setter. If he is far from the net and it is considered that he can no longer carry out a force attack, he starts from the block, and each partner will defend half of the court from the back area of the court. This can be the key to success against many teams.

At a high level, even if many would be tempted to leave the net, as it was established that if the opponent failed to make a good reception, the setter could bring the ball in a favorable attacking position from any position on the court. That is why the blocking player has to stay on guard until he is one hundred percent convinced that his opponents will no longer attack by force and can retreat behind the court to the place before his teammate.

The primary data of modern volleyball is obtained through statistical procedures, which can identify the strengths and weaknesses of the opponent team. Coaches use these data to train other teams and achieve expected results (Szabo and Magdas, 2014; Szabo, 2015a; Szabo, 2015b; Szabo and Sopa, 2015; Szabo et al., 2019; Szabo and Sopa, 2018). From an interdisciplinary perspective, we want to emphasize proprioception (Szabo et al., 2020; Szabo et al., 2020b; Szabo and Sopa 2020), strength motor skills (Tulbure et al., 2020), biomechanics, and Psychomotor 
skills (Szabo et al., 2020c; Szabo et al., 2020d), and modern smart methods in beach volleyball matches (Szabo et al., 2019b).

\section{The reason the block is used}

The block is fundamental in the game of beach volleyball from a certain level of play. When the level of officially or unofficially games reaches a reasonable level where the two teams manage to quickly bring their ball around the net in a clear attacking position, and their physical and motor qualities allow them to perform this type of action, then it is clear that the defensive team needs to use its entire arsenal of procedures and technical elements in order to obtain the point. One of them is blocking, which can be performed in several ways. The defense must differ almost every time at the professional level, so opponents never know what to expect from the player on the block.

Most of the time, players start by designating their order at the block so that the player performing the block is close to the net. Team strategies are usually established before the start of the match, but often players choose the option in which in the first points played until the teams get to know each other, the player from the block will jump and defend the straight line against the opponent's attack. The blocking player must be conscientious and watch the ball from the moment it passes the net and is in the opponent's court. This aspect is essential as opponents can return the ball after any contact, not necessarily after the third. In this sense, the blocking player must constantly move in front of the net, usually using the move with added steps and permanently in front of the ball circulates between the two opponents. Thus, even if the opposing team has excellent reception and manages to send the ball in the attacking position from the first touch, the block is ready and can intervene very quickly, and if it does not move in the direction from where the player who made the reception, will be in the attacking position.

The decision strategies of the defensive players have been investigated recently. Kredel et al. (2011) demonstrated that in a training situation, elite male defense players initiate their movement at $250 \mathrm{~ms}$ after contact of the ball with the opponent's hand. Elite female defensive players start their movement earlier, about $110 \mathrm{~ms}$ after the ball contacts their hand. Amateur players initiate their movement even earlier. The decision correction was $95 \%$ for male elite players and $81 \%$ for female elite players. In the training situation, only visual stimuli could be processed. Kredel et al. (2011) did not consider any auditory stimulus as an appeal. However, in a qualitative study, Schläppi-Lienhard and Hossner (2014) interviewed world-class athletes about their decision-making process in defense situations. Only one of the 19 athletes interviewed mentioned that the opponent's call influenced his decision. Schläppi-Lienhard and Hossner (2014) concluded that, for the defending player, the opponent's call played a minor role at best. However, some internationally successful teams avoid their call being used by opponents by calling codes in their native (non-English) language, which opponents cannot decode in time. It is essential that the player from the net jumps to the block as high as possible and tries to block the ball on a wide aisle so that the player behind is much helped by the area covered by his partner and can position himself to defend the free surface. Blocking 
as high as possible forces the opponent to send the ball with much height over the block, and the defender increases the chances of reaching the ball, as the time the ball spends in the air before contact with the ground is longer.

The blocking player needs to make a slight pivot to the center of the ground when it comes off the ground so that, if hit by the ball, it bounces in the opponent's court, not out of bounds. Also, the person performing the block must coordinate his jump very well from a material point of view so that it takes place a fraction of a second later than that of the opposing attacker. His hands must be perfectly stretched and held as rigid as possible, rises above the opponent's net, and, eventually, according to the rules, passes beyond the upper lane in an attempt to close as much as possible, the opponent's angle of attack.

Detachment from the sand in the execution of the block is done in the same way as in the attacking momentum, using the technique described above, heel-soletoe, which makes the player from the block not move horizontally and touch the net, thus granting a point unworked to his opponents.

\section{The movement of feet in the technique of blocking}

Unlike indoor volleyball, where the movement is done almost every time by sidestepping and then detaching from the floor as high as possible, in technical beach volleyball, blocking movement differs because it is not always done by side stepping because it is not always done by sidestepping slower.

The player from the block to gain time often moves in a straight line, parallel to the net, performs the detachment beat by the technique mentioned heel-sole-toe, and when he is in the air, turns his shoulders to the net, the line described by them being at the moment of contact with the ball parallel to the net. If the blocking player waits for the ball somewhere at a distance of 3 meters, when he will hurry to reach the net to perform the blocking, it is more than sure that the detachment will not be done only vertically and horizontally, and the effect it will be the unwanted contact with the net.

\section{Determination at the block}

Any defensive player who executes the block must first be very determined when he has committed to block a particular area of the field; that aspect must be clear in his task and in no way remain uncovered. Otherwise, the defense mechanism between the two partners will suffer severe damage, and the match will fail. Karch Kiraly, one of the greatest American champions in the history of this beautiful sport, managed to win countless AVP Pro tournaments with several partners because, being the blocking player, he performed this technical procedure so correctly and efficiently that the players who activated behind him knew exactly what exposed areas he needed to defend. Karch Kiraly was given a chance to change things around. It was about how Karch jumped to the block, knowing that he had to defend the straight line, and when he was sure that area was secure, he lowered his arms to the inside of the field, covering a large part of the field diagonals left to the defender. Thus, his teammate in the back had very few chances left to receive the 
ball, and if he managed to place himself where his defensive zone was, most of the time, they recovered that ball.

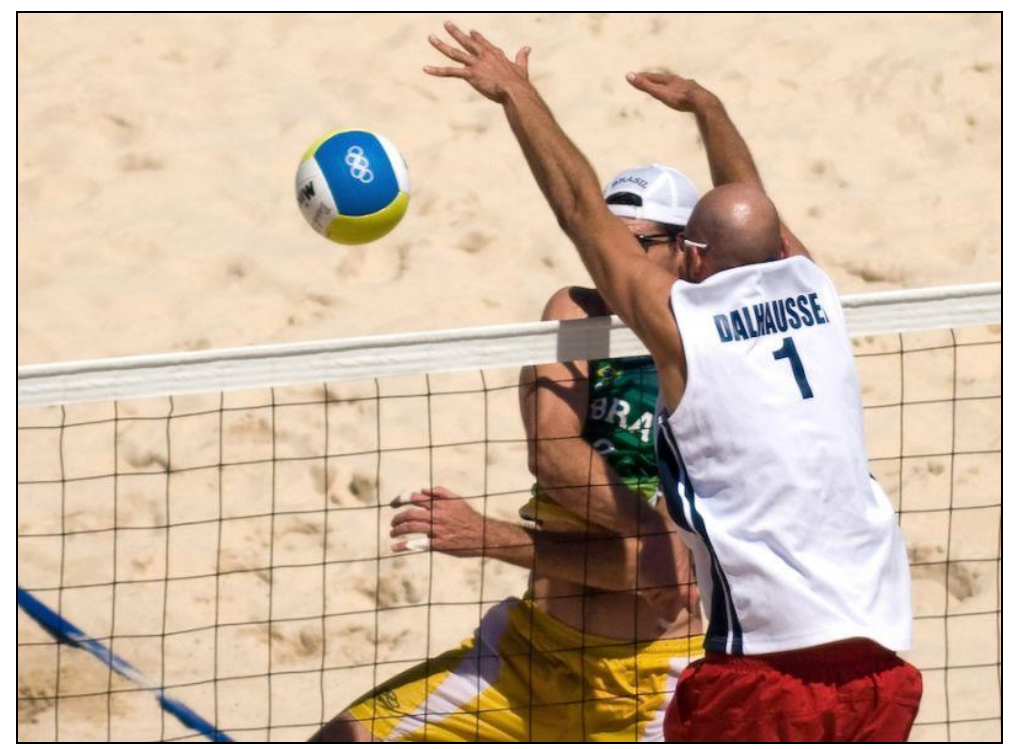

Figure 1. Blocking line ${ }^{1}$

\section{False block}

In this regard, perhaps more than in the others, we must insist on communication between partners who strive to be perfect. This aspect can distinguish between winning or not confident balanced partied where the difference is made at a regular minimum of 2 points. For players who block in their team, the false block jump is significant.

If a player jumps to the block several times in a row and fails to be effective, he must communicate with his partner and understand as well as possible how the one in the net will retreat backward, either in a straight line or diagonally. Once the opposing team starts to place balls to the detriment of the attacking shots, it is clear that the defenders must change their strategy and not jump to the block and defend against the balls placed on the field.

It is imperative when the net will trigger the retreat backward to maximize the effect against the opponents. This is done at the last moment when the opponent is already near the moment of hitting the ball. It does not have to retract after the reception of the other, even if it is not as perfect as after the setting step.

The player from the block retires when the opponent takes his eyes off the defensive team, and his peripheral gaze no longer helps him to realize where the players are positioned. This can be misleading, as opposing players may already be in a position to wait for a placed ball, and the point will return to them. A false block is used when the blocking efficiency is low; the opponents manage to attack almost any ball next to the defender, or on the contrary, they place the balls with serenity in

\footnotetext{
1 https://jvavolleyball.org/7-keys-blocking-beach-volleyball/
} 
the defenders' court. No matter how good is the blocking in a beach volleyball match, the strategy cannot be maintained from the start of the match until the end. Alternatives are needed, and false blocking is very effective.

\section{The "v" block}

This particular type of blocking is performed when the opposing attacker is in a position to attack from the middle of the field, a position in which the defender from the back of the court has $90 \%$ of the court compared to $70 \%$ in most cases when the attacker hits the ball either to the left or to the right of the net.

The ability to jump can be considered a determining factor of performance in the game of beach volleyball (Palao et al., 2014). Therefore, monitoring tools and methods to accurately measure and control biomechanical jump variables are essential to improve training and performance. Inertial measurement units (IMUs) offer a promising alternative for court diagnosis and have already been used to determine the height of jumps in indoor volleyball (e.g., Charlton et al., 2017). On the beach, players are forced to adapt their movement patterns and produce different movement dynamics (Schmidt et al., 2019).

Given that the opening field for the attacker is vast, the defender who jumps to the block opens both arms wide in a V-shape, leaving a space above the head. That is the area that the back defender should defend first, and then if the ball is placed to try to reach the mouth where it tends to touch the sand.

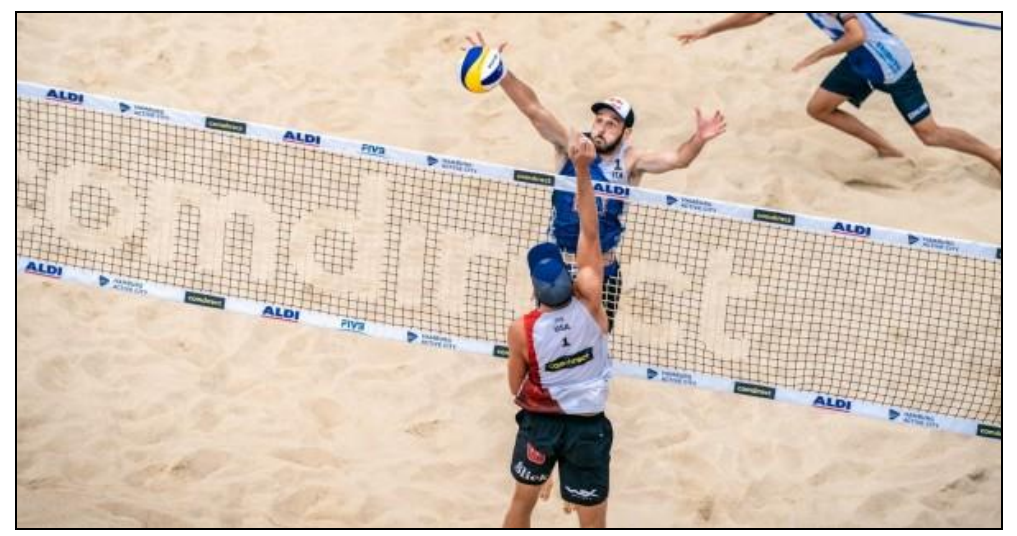

Figure 2. The $\mathrm{V}$ block $^{2}$

\section{Misleading the opponent}

A very effective strategy in managing decisive blocks is not to let opponents get used to how the block is executed in the sense of executing a simple routine on each ball attacked by opponents. This will lead one hundred percent to an advantage on the opposing team that will know precisely how to defend and implicitly will find multiple ways to avoid blocking. This can be counteracted in several ways, but one of the most effective ways would be to mislead opponents. Thus, if the agreement 
between the defenders is that the block defends the line, the rear defender will make some slots trying to mislead opponents about the location where he will position himself for the defense phase, but each time it will be positioned diagonally, the area assigned to him on the defensive phase. This will have to be done by the block, namely, to give the impression that he will choose to jump to the block, appearing diagonally and jump and defend the line. This is done as follows: it is agreed that the player who jumps to the block must detach a fraction of a second later than the attacker on the sand.

When the attacker detaches himself from the sand and performs the "bow and arrow" movement to hit the ball, the defender is in front of him as if defending diagonally but taking advantage of the split-second available until the moment of detachment. Of sand, it will at the last moment take a lateral step towards the line that it will defend by jumping and will detach itself strongly from the sand by the mentioned technique "heel-sole-toe" and will block that area. Thus, the opposing attacker will be misled because, at the time of his detachment from the sand, the defender was able to defend diagonally, and later, he defends the line. In this strategy, it is imperative to communicate with the two teammates and not to change the way of defense in any form as they will wake up in the position of both defending the same area of the field, thus giving half of the field accessible to opponents.

\section{Conclusion}

As we speak about beach volleyball the scoreboard is influenced primarily by the attack phase of the game, which grants points and also generate the show so loved by the audience, but we must be aware that before this offensive aspect of the game, its defensive side has an essential role for the subsequent construction of the attack phase. It is practically impossible to reach the attack phase if a good serve receive is not easy playable or if a ball is not recovered in the transition phase.

Defensive strategies are based primarily on a very good communication between the two partners, this aspect being essential in their path to success as a team.

These strategic aspects of the beach volleyball game are based primarily on a solid defense. It is based on the execution of specific technical procedures in a way executed as correctly as possible, the first and perhaps the most important of these being the block. If this technical element is executed correctly and efficiently, the chances of success of the defensive phase increase significantly because this is the element that coordinates all the others: the transition, the dive of the defender, the moving skills in the field done by the defensive player and the field orientation and positioning behind the block.

\section{References}

Afonso, J., Mesquita, I., Marcelino, R., \& Coutinho, P. (2008). The effect of the zone and tempo of attack in the block opposition, in elite female volleyball. In Book of Proceedings of the World Congress of Performance Analysis of Sport VIII, Magdeburg (pp. 412-415).

Bizzocchi, C. (2008). O voleibol a alto nível: da iniciação à competição. 2ed. Barueri, SP: Manole.

Busca, B., \& Febrer, J. (2012). Temporal fight between the middle blocker and the setter in high level volleyball. Revista Internacional de Medicina y Ciencias de la Actividad Física y del Deporte, 12(46), 313-327. 
Castro, J., Souza, A., \& Mesquita, I. (2011). Attack efficacy in volleyball: elite male teams. Perceptual and Motor Skills, 113(2), 395-408.

Ciccarone, G., Croisier, J.L., Fontani, G., Martelli, G., Albert, A., Zhang, L., \& Cloes, M. (2008). Comparison between player specialization, anthropometric characteristics and jumping ability in top-level volleyball players. Medicina Dello Sport, 61(1), 29-43.

Ciccarone, G., Fontani, G., Albert, A., Zhang, L., \& Cloes, M. (2005). Analysis of anthropometrics characteristics and jumping ability in junior top level volleyball athletes. Medicina Dello Sport, 58(1), 1-15.

Cortell-Tormo, J.M., Perez-Turpin, J.A., Chinchilla-Mira, J.J., Cejuela, R., \& Suarez, C. (2011). Analysis of movement patterns byelite male players of beach volleyball. Perceptual and Motor Skills, 112(1), 21-28.

FIVB (2016). Official Beach Volleyball Rules 2017-2020.

Jimenez Olmedo, J.M., Penichet Tomas, A., Saiz Colomina, S., Martinez Carbonell, J.A., \& Jove Tossi, M.A. (2012). Serve analysis of professional players in beach volleyball. Journal of Human Sport and Exercise, 7(3), $706-713$.

Jimenez-Olmedo, J.M., Pueo, B., Penichet-Tomás, A., Chinchilla-Mira, J.J., \& Perez-Turpin, J.A. (2017). Physiological work areas in professional beach volleyball: A case study. Retos. Nuevas Tendencias en Educación Fisica, Deporte y Recreación, 31, 94-97.

Koch, C., \& Tilp, M. (2009). Beach volleyball techniques and tactics: a comparison of male and female playing characteristics. Kinesiology, 41(1), 52-59.

Kredel, R., Klostermann, A., Lienhard, O., Koedijker, J., Michel, K., \& Hossner, E.J. (2011). Perceptual skill identification in a complex sport setting. In BIO Web of Conferences (Vol. 1, p. 00051). EDP sciences.

Lajtai, G., Pfirrmann, C.W., Aitzetmuller, G., Pirkl, C., Gerber, C., \& Jost, B. (2009). The Shoulders of Fully Competitive Professional Beach Volleyball Players: High Prevalence of Infraspinatus Atrophy. The American Journal of Sports Medicine, 37(7), 1375-1383.

Lehnert, M., Lamrova, I., \& Elfmark, M. (2009). Changes in speed and strength in female volleyball players during and after a plyometric training program. Acta Universitatis Palackianae Olomucensis Gymnica, 39, 59-66.

Lidor, R., \& Ziv, G. (2010). Physical and physiological attributes of female volleyball players-a review. Journal of Strength and Conditioning Research, 24(7), 1963-1973.

López-Martinez, A.B., \& Palao, J.M. (2009). Effect of serve execution on serve efficacy in men's and women's beach volleyball. International Journal of Applied Sports Sciences, 21(1), 1-16.

Marcelino, R., Mesquita, I., Sampaio, J., \& Moraes, J. C. (2010). Estudo dos indicadores de rendimento em voleibol em função do resultado do set. Revista Brasileira de Educação Física e Esporte, 24(1), 69-78.

Marques, M.C., van den Tillaar, R., Gabbett, T.J., Reis, V.M., \& González-Badillo, J.J. (2009). Physical fitness qualities of professional volleyball players: determination of positional differences. Journal of Strength and Conditioning Research, 23(4), 1106-11.

Palao, J.M., Gutierrez, D., \& Frideres, J.E. (2008). Height, weight, Body Mass Index, and age in beach volleyball players in relation to level and position. Journal of Sports Medicine and Physical Fitness, 48(4), 466-471.

Palao, J.M., Valadés, D., Manzanares, P., \& Ortega, E. (2014). Physical actions and work-rest time in men's beach volleyball. Motriz: Revista de Educação Física, 20(3), 257-261.

Pastore, J.C.F., Ferreira, C.A.A., Costa, F.C.H., \& Joao, P.V. (2015). Case study: Proposal for training in combined plyometrics and muscular strength in improved vertical jump in beach volley. International Journal of New Technology and Research (IJNTR), 2(5), 30-33.

Peña, J., Rodríguez-Guerra, J., Buscà, B., \& Serra, N. (2013). Which skills and factors better predict winning and losing in high-level men's volleyball? Journal of Strength and Conditioning Research, 27(9), 2487-2493.

Pereira, A., Costa, A.M., Santos, P., Figueiredo, T., \& João, P.V. (2015). Training strategy of explosive strength in young female volleyball players. Revista Medicina, 51, 26-131.

Perez-Turpin, J.A., Cortell-Tormo, J.M., Chinchilla-Mira, J.J., Cejuela-Anta, R., \& Suarez-Llorca, C. (2009). Performance analysis through the use of temporal activity patterns of elite players inbeach volleyball. Retos. Nuevas Tendencias En Educación Fisica, Deporte y Recreación, 16, 67-69.

Pfirrmann, C.W., Jost, B., Pirkl, C., Aitzetmuller, G., \& Lajtai, G. (2008). Quadriceps tendinosis and patellar tendinosis in professional beach volleyball players: sonographic findings in correlation with clinical symptoms. European Radiology, 18(8), 1703-1709. 
Pomohaci, M., \& Sopa, I.S. (2018). Discovering the cohesion of a volleyball team and finding the right leader of the group. Revista Academiei Fortelor Terestre, 23(1), 58-64.

Popa, C.O., Schenk, A., Rus, A., Szasz, S., Suciu, N., Szabo, D.A., \& Cojocaru, C. (2020). The Role of Acceptance and Planning in Stress Management for Medical Students. Acta Marisiensis-Seria Medica, 66(3), 101-105.

Riggs, M.P., \& Sheppard, J.M. (2009). The relative importance of strength and power qualities to vertical jump height of elite beach volleyball players during the counter-movement and squat jump. Journal of Human Sport and Exercise, 4(3), 221-236.

Schläppi-Lienhard, O., \& Hossner, E.J. (2015). Decision making in beach volleyball defense: Crucial factors derived from interviews with top-level experts. Psychology of sport and exercise, 16, 60-73.

Sheppard, J.M., Cronin, J.B., Gabbett, T.J., McGuigan, M.R., Etxebarria, N., \& Newton, R.U. (2008). Relative importance of strength, power, and anthropometric measures to jump performance of elite volleyball players. Journal of Strength and Conditioning Research, 22(3), 758-765.

Smith, R. (2006). Movement in the sand: training implications for beach volleyball. Strength and Conditioning Journal, 28(5), 19-21.

Sopa, I.S. (2019). Developing attack point in volleyball game using plyometric exercises at 13-14 years old volleyball players. Bulletin of the Transilvania University of Brasov. Series IX, Sciences of Human Kinetics, 12(2), 67-76.

Sopa, I.S. (2021). Assessing the anxiety level of a volleyball team. Geosport for Society, 14(1), 47-55.

Sopa, I.S., \& Pomohaci, M. (2018). Discovering the leader of a volleyball team using the sociometric survey method. Timisoara Physical Education and Rehabilitation Journal, 11(20), 27-33.

Sopa, I.S., \& Pomohaci, M. (2021). Using coaching techniques in assessing and developing the static and dynamic balance level of young volleyball players. Bulletin of the Transilvania University Brasov, 14(63), 89-100.

Sopa, I.S., \& Szabo, D. A. (2019). Statistical comparison related to service and reception of volleyball team CSM Volei Alba Blaj in the CEV Champions League Final Four 2018. Timisoara Physical Education and Rehabilitation Journal, 12(23), 16-25.

Sopa, I.S., \& Szabo, D.A. (2020). Comparison between statistical parameters of attack and defense in high volleyball performance (CSM Volei Alba Blaj in the CEV Champions League Final Four 2018). Bulletin of the Transilvania University of Brașov, 13(1), 93-102.

Szabo, D.A. (2015a). Modalities of using the information provided by the statistical program click and scout for improving the outside hitters' service efficiency in volleyball game. The European Proceeding of Social \& Behavioral Sciences EpSBS, 341-347.

Szabo, D.A. (2015b). Study on improving the service unforced errors in volleyball game by using a statistical software. In Conference proceedings of» eLearning and Software for Education «(eLSE) (No. 03, pp. 320-326). " Carol I" National Defence University Publishing House.

Szabo, D.A., \& Magdaș, L. (2014). Increasing the defensive efficiency in volleyball using the statistical program "Click\&Scout". Conference proceedings of eLearning and Software for Education (eLSE), Issue 1, 223-228.

Szabo, D.A., \& Sopa, I.S. (2015). Study on the Interpretation of the Results in a Volleyball Game by Using a Specific Program of Statistics. Procedia Social and Behavioral Sciences, Elsevier Publication, Volume 180C, p. 1357-1363.

Szabo, D.A., \& Sopa, I.S. (2018). Preventing shoulder injuries using prophylactic programs for volleyball players. Discobolul - Physical Education, Sport and Kinetotherapy Journal, 14(53), 49-57.

Szabo, D.A., \& Sopa, I.S. (2020). Study regarding the level of physical and functional development of children from primary school level. Journal of Physical Education and Sport, 20(3), 1497-1504.

Szabo, D.A., Neagu, N., \& Sopa, I.S. (2020). Research regarding the development and evaluation of agility (balance, coordination and speed) in children aged 9-10 years. Health, Sports \& Rehabilitation Medicine, 21(1), 33-40.

Szabo, D.A., Neagu, N., Teodorescu, S., \& Sopa, I.S. (2020b). Eye-hand relationship of proprioceptive motor control and coordination in children 10-11 years old. Health Sports Rehabil. Med, 21, 185-191.

Szabo, D.A., Neagu, N., \& Sopa, I.S. (2020c). Kinematic angular analysis of cinematic biomechanics in forearm flexion: a case study. Geosport for Society, 13(2), 140-148.

Szabo, D.A., Neagu, N., Ardelean, M., \& Sopa, I. S (2020d). Psychomotor evaluation of athlete and nonathlete children. Discobolul - Physical Education, Sport and Kinetotherapy Journal, 59, 56-69. 
Szabo, D.A., Neagu, N., Teodorescu, S., Pomohaci, M., \& Sopa, I.S. (2019). Modalities of Exploitation the Information Provided by the Click\&Scout Statistical Program in Preparing Volleyball Attack Players. International Journal of Applied Exercise Physiology, 8(2.1), 804-811.

Szabo, D.A., Neagu, N., Teodorescu, S., Pomohaci, M., \& Sopa, I.S. (2019b). Does Smart Electronic Devices Influence the Body Deficiencies Development at Kids Who Practice Swimming?. International Journal of Applied Exercise Physiology, 8(2.1), 845-851.

Szabo, D.A., Sopa, I.S., Stoica, R.S., \& Ivănescu, A. (2018). The effectiveness of physiotherapeutic treatment in the recovery of the collateral ligament lesion. Discobolul - Physical Education, Sport and Kinetotherapy Journal, 14(52), 16-24.

Tilp, M., Wagner, H., \& Muller, E. (2008). Differences in 3D kinematics between volleyball and beach volleyball spike movements. Sports Biomechanics, 7(3), 386-397.

Tulbure R.E., Neagu N., \& Szabo, D.A. (2020). Comparative study on the development of the motor skill (strength) through the circuit method versus dynamic games in physical education classes. Health, Sports \& Rehabilitation Medicine, 21(4), 223-230.

Zetou, E., Giatsis, G., Mountaki, F., \& Komninakidou, A. (2008). Body weight changes and voluntary fluid intakes of beach volleyball players during an official tournament. Journal of Science and Medicine Sport, 11, 139-145.

https://jvavolleyball.org/7-keys-blocking-beach-volleyball/

https://beachmajorseries.com/en/3028/the-five-best-male-blockers-of-the-major-series 